\title{
Effect of water-repellent admixtures on the behaviour of aerial
}

\section{lime-based mortars}

\author{
A. Izaguirre ${ }^{\mathrm{a}}$, J. Lanas ${ }^{\mathrm{b}}$, J.I. Álvarez ${ }^{\mathrm{a}, *}$ \\ ${ }^{a}$ Department of Chemistry and Soil Sciences, School of Sciences, University of Navarra, c/ Irunlarrea, 1, \\ 31008, Pamplona, Spain \\ ${ }^{b}$ CTH Navarra, Polígono Talluntxe II C/M, 10, 31192, Tajonar, Spain
}

$\mathbf{N}^{\mathbf{0}}$ of pages: 48

$\mathbf{N}^{\mathbf{0}}$ of tables: 7

$\mathbf{N}^{\circ}$ of figures: 9

Keywords: D. Admixture; C. Durability; C. Freezing and Thawing; C. Mechanical properties; Lime mortar

*Dr. Jose I. Alvarez Galindo

Dpto. de Química

Fac. de Ciencias

Universidad de Navarra

$\mathrm{C} /$ Irunlarrea, 1

31.080 Pamplona (Navarra)

Spain

Phone: 34948425600

Fax: 34948425649

E-mail: jalvarez@unav.es 


\title{
Effect of water-repellent admixtures on the behaviour of aerial
}

\section{lime-based mortars}

\author{
${ }^{\mathrm{a}}$ A. Izaguirre, ${ }^{\mathrm{b} J}$. Lanas, ${ }^{\mathrm{a} J . I . ~ A ́ l v a r e z *}$ \\ ${ }^{a}$ Department of Chemistry and Soil Sciences, School of Sciences, University of Navarra, c/ Irunlarrea, 1, \\ 31008, Pamplona, Spain \\ ${ }^{b}$ CTH Navarra, Polígono Talluntxe II C/M, 10, 31192, Tajonar, Spain
}

\begin{abstract}
Two different anionic surfactants, sodium oleate and calcium stearate, commercialized as water repellents for cement-based mortars, were added to lime-based mortars in order to check whether they were improved by these admixtures. Different properties of limebased mortars were evaluated: fresh state behaviour through water retention, air content and setting time, hardened state properties such as density, water absorption through capillarity, water vapour permeability, long-term compressive strengths, pore structure through mercury intrusion porosimetry, and durability assessed by means of freezingthawing cycles. A clear improvement in lime-based mortars was achieved when sodium oleate was added: strong capillarity reduction and excellent durability in the face of freezing-thawing processes, without any compressive strength drop. The mechanism for this improvement was related to air void formation due to the air entraining ability of these surfactants. Insolubility of calcium stearate turned out to be responsible for fewer air bubbles - as SEM examination revealed - and showed lower effectiveness.
\end{abstract}




\section{Introduction}

Recently, there has been increased scientific interest in lime-based mortars and their uses. Several drawbacks and incompatibilities related to the use of cement mortars for Cultural Heritage restoration work have been highlighted: high mechanical strength, efflorescence phenomena owing to formation of large amounts of soluble salts by migration of alkaline ions, low water vapour permeability and higher thermal expansion coefficient than most masonry [1-4]. In view of these shortcomings, lime-based mortars show greater compatibility with ancient building materials and fulfil the recommendations of ICCROM [5] about the use of materials similar to the original ones in repair works.

Many different characteristics of lime-based mortars have been studied: RodriguezNavarro et al. reported the effect of ageing lime putty on $\mathrm{Ca}(\mathrm{OH})_{2}$ crystal evolution and its consequences during mortar carbonation $[6,7]$. Atzeni et al. and Arandigoyen et al. conducted research into fresh state properties and pore structure and capillary porosity, respectively, of lime pastes $[8,9]$, while rheological behaviour of lime mortars was discussed by Seabra et al. $[1,10]$. Other authors have carried out research on the carbonation, long-term mechanical behaviour and durability of aerial, dolomitic and hydraulic lime mortars $[11,12]$.

However, some problems related to the use of aerial lime-based mortars still remain such as: i) long setting and hardening time; ii) relatively low mechanical strength; iii) a high water absorption capacity through capillarity; iv) major volumetric change as a result of shrinkage [4]. In order to reduce or even solve these problems, the use of 
admixtures might be considered. In the field of cement mortars, the use of admixtures, substances added in percentages lower than $5 \%$ with the purpose of improving certain mortar properties, has been widely researched [13-16]. In this context, water-retaining agents, water repellents, air-entraining agents (AEA's), water reducers or superplasticizers can be cited. In spite of their widespread use in cement mortars or concrete, very few studies have focused on the effect of admixtures on aerial lime-based mortars: Cultrone et al. [17] concluded that carbonation process were not affected by additives (an AEA and/or a natural pozzolana). They also reported an increase in the number of macropores when an AEA - a fatty alcohol derived - was added, with a significant reduction of retraction fissures taking place. Seabra et al. [1] gave details on fresh state behaviour of aerial lime-based mortars modified with a water-retaining agent, a plasticizer and an AEA. Fortes-Revilla et al. studied the addition of a superplasticizer in slaked lime-metakaolin mortars, reporting increased strength and reduced porosity [18]. Maravelaki-Kalaitzaki [19] reported the behaviour of hydraulic lime mortars treated with an oligomeric organo-siloxane water repellent applied by brushing on hardened specimens.

This last kind of admixtures - water repellents, generally added to the fresh mixture have been extensively studied in cement based mortars [20, 21], but little is known about the effect of these additives if they are incorporated into aerial lime-based mortars. A group of very interesting chemical compounds commercialized as water repellents for cement mortars is the fatty acid salts (such as sodium oleate, SO, and calcium stearate, CS). These molecules - anionic surfactants - have also been reported in the scientific literature on cement mortars like AEAs [22-25], and they can also be found as additives which improve the processability of gypsum plaster composition 
[26], acting as lubricants. SO and CS are characterized by a long non-polar hydrocarbon chain and a polar group at one end, thus having a bipolar nature. As a consequence, they may be adsorbed and concentrate at the air-paste interface, usually in the air bubble surface. This fact causes reinforcement of the air bubbles and avoids coalescence [2224]. Atahan and co-workers reported that when they mixed SO solutions with cement or $\mathrm{Ca}(\mathrm{OH})_{2}$, precipitants of calcium oleate were formed (just like soap). This fact considerably reduced the availability of oleate for air-entraining action. Nevertheless, precipitant adsorption on the bubbles' surfaces stabilized them, even though hardened cement pastes treated with SO showed fewer air voids than pastes treated with synthetic detergents like sodium dodecyl sulfate or sodium dodecyl-benzene sulfonate [22].

Air voids improve the durability of cement-based mortars and concrete, especially by protecting mortars from freeze-thaw conditions. Moreover, entrained air enhances workability, leading to a reduction of the water/cement ratio, thus resulting in more impermeable materials [27].

According to the available information and common practice, these anionic surfactants, sodium oleate and calcium stearate, are probably all-purpose admixtures, although no mechanism of action has been proposed for their water-repellent effect. In the present study, the behaviour of aerial lime-based mortars modified with two different fatty acid salts - SO and CS - is reported. Fresh state properties, capillarity, mechanical strength in long-term studies as well as durability tests (freezing-thawing cycles) will allow to draw conclusions about the improvement of aerial lime-based mortars.

\section{Materials}


An aerial commercial lime and a pure limestone aggregate were used to prepare the mortars. The lime (class CL 90-S according to Spanish standard [28]) was supplied by Calinsa (Navarra). The aggregate was supplied by Caleras de Liskar (grupo HORPASA). This aggregate was a calcareous one employed in previous research works conducted on lime-based mortars [2, 29, 49]. Figures 1 and 2 present the mineralogical composition of the lime and aggregate used (obtained by X-ray diffraction) and their granulometric distributions, respectively. The selected binder: aggregate ratio (B:Ag) was $1: 1$, by volume. This decision was taken according to previous data $[2,29]$. Volume proportions were converted in weight in order to avoid any imprecise measurement (Table 1). Five different dried mixtures were prepared. One of them was composed only of lime and aggregate, and was considered as a reference mortar. One only additive was incorporated in each one of the remaining mortars, in order to check clearly its possible efficiency, avoiding other variables. For each additive, two different dosages were proved: $0.06 \%$ and $0.5 \%$ of the total dried mortar's weight. The first dosage was selected because it is one of the most common dosages used in the literature for this kind of admixture [20, 22, 27]. The second one was chosen because it involves a very different amount of additive, which is supposed to change the material more dramatically, and it has been previously used in published research [21, 30]. The additives used were obtained from a supplier as commercial products: HISA-A $2388 \mathrm{~N}$ (sodium oleate, SO in the current paper) from ADI-center-S.L.U. and ETP-09 (calcium stearate, CS in this paper) from Mateos S.L. Furthermore, pure sodium oleate and calcium stearate (Sigma-Aldrich) were used, in order to compare the commercial additives. Figure 3 shows the IR spectra of additives and pure SO and CS, showing the total similarity between them. 


\section{Methods}

\subsection{Foam index test}

The foam index test purposed by Corr [25] and modified by Atahan [22] was used as an effective method to predict the compatibility between lime and SO and CS, respectively. Furthermore, during the execution of this test, the behaviour of each one of the additives in contact with water was also observed. The steps of the test were the following:

- Two different test tubes were prepared for each water-repelling agent, by dissolving $0.025 \mathrm{~g}$ of additive in $50 \mathrm{~mL}$ of distilled water.

- $0.2 \mathrm{~g}$ of lime was incorporated in one of the two test tubes of each additive.

- The four test tubes were shaken for 15 seconds, and the foam level in each case was noted down.

- After resting 5 minutes, the foam level was analysed again.

The change in volume between the two measurements was an indication of the foam stability in each case. The difference between the foam index with and without lime for each additive was an indication of the compatibility between the binder and this additive.

The method purposed by Ouyang et al. [27] was followed in order to estimate the amount of SO and CS that could be adsorbed on the binder surface. In their study, the adsorption of the admixture on the cement surface led to a better dispersion of the 
binder in water and, therefore, better hydration. In the current study, although there is no hydration reaction, the correct dispersion of lime could be decisive to determine the final properties of the mortar.

The concentration of the additive in water solution and the remaining concentration after the lime was added were determined using a UV-vis spectrometer Hewlett-Packard 8452 at a wavelength of $270 \mathrm{~nm}$.

\subsection{Mortar preparation}

The amount of water was set in order to achieve a mortar slump of $160 \pm 10 \mathrm{~mm}$ after the flow table test, followed according to the method of UNE-EN 1015.3: 2000. This method is based on the measurement of the spread of slurry placed into a cone-shaped mould. When the mould, filled with fresh mortar, is vertically lifted, 15 knocks of the table take place during 15 seconds, and the slump is determined. This value allowed good workability, while avoiding an excess of water which would have been damaging for mechanical strengths [2].

The mixer used was a Proeti ETI 26.0072. Lime, aggregate and additive, if necessary, were blended for 90 seconds at low speed. Water was then added and mixed for 90 more seconds at low speed. Mortars settled for 10 minutes before being tested, to let the additive take effect. Straight afterwards, fresh state properties were determined as described below. Table 1 shows the amount of water of the five different mixtures.

\subsection{Rheological properties}


For the fresh state, several properties were studied: consistency through the flow table test, by measuring the slump after the procedure [31]; density ; air content, both data being recorded using a receptacle of $1 \mathrm{dm}^{3}$ previously weighted, which, after being filled with fresh mortar, was weighted again to obtain the density [32]. In a specific device, the entrained air was removed and replaced by a measurable amount of introduced water, which allowed to determined the air content [33]; water-retention capacity, determined by weighting absorbent materials placed on the fresh sample before and after 5 minutes of contact under pressure [34]; setting time, obtained from a specific device provided with a bradawl, which pushed the fresh sample until the strength exerted to introduce it into the sample was larger than $15 \mathrm{~N}$ [35]; and evolution when applied on support, This last test consisted of spreading a $15 \mathrm{~mm}$ layer of mortar on a brick and checking the evolution.

\subsection{Hardened mortar properties}

At hardened state, analysis of density, water absorption through capillarity [36], water vapour permeability [37], shrinkage, pore size distribution (by means of mercury intrusion porosimetry) and microstructure examination (using scanning electron microscopy with an EDS) were carried out. Furthermore, different test specimens were prepared in order to study the mechanical strength at different times (from 7 to 365 days). Durability was also studied through freezing-thawing cycles.

\subsubsection{Mechanical strengths}


Mortars were moulded in prismatic 40×40×160 mm casts and de-moulded 5 days later [38]. Pastes were compacted in a specific device for 60 seconds (meter la explicacion del borrador de JI?). Curing was performed in ambient laboratory conditions until the test day (RH $60 \pm 10 \%$ and $20 \pm 5^{\circ} \mathrm{C}$ ). A total of fifteen specimens were prepared for each mixture; hence, 75 specimens were studied. Different curing times were set: 7, 28, 91, 182 and 365 days; 3 specimens of each mortar were tested at each curing time in order to make results representative. The reported results are an average of all of them. Compressive strength tests were executed on a Proeti ETI 26.0052, and the rate of loading was $50 \mathrm{~N} \cdot \mathrm{s}^{-1}$.

\subsubsection{Density and shrinkage}

The specimens used for the shrinkage and density at hardened state tests were those prepared for determining mechanical strength. Before the specimens were broken during the mechanical test, their length was measured with a gauge and the mass was set with a balance.

\subsubsection{Pore structure and microstructure}

Pore size distribution test was performed by using a Micromeritics AutoPore IV 9500 with a range of pressure between 0 and $207 \mathrm{MPa}$. Pressure, pore diameter and intrusion volume were automatically registered. 
Finally, microstructure examination through scanning electron microscopy, with a Digital Scanning Microscopy Philips XL 30CP with EDS/EDAX Phoenix, was executed on different hardened mortars.

\subsubsection{Freezing-thawing cycles}

In order to test the efficiency of the water-repelling agents, specimens with the highest dosage of admixtures were subjected to durability cycles and compared to the reference group. Only the mortars with high dosage of additive were used, owing to their better water-absorption capillarity results.

Mortars were prepared as aforementioned in 3.4.1. Curing was executed in ambient laboratory conditions over 56 days (RH $60 \pm 10 \%$ and $20 \pm 5^{\circ} \mathrm{C}$ ), and after that, samples were subjected to several freezing-thawing cycles. They were immersed in water until complete saturation and then frozen in a freezer at $\left(-10^{\circ} \mathrm{C} \pm 2^{\circ} \mathrm{C}\right)$. A total of ten specimens were prepared for each mixture; hence, 30 specimens were studied. Different testing days were set corresponding to $1,4,7,10$ and 14 complete cycles. Weight exchange, qualitative alteration according to a previously proposed criterion [39] and compressive strengths were studied. Two specimens of each mortar were tested at each time, and the reported results are an average of the two. Table 2 shows the characteristics of the set cycles.

\section{Results and discussion}

\subsection{Foam index test}


After each one of the additives was added to the water, it could be noticed that while SO dissolved perfectly, CS formed a separate layer on the water. This fact can be easily related to the solubility differences between the admixtures (sodium oleate ca. 10\%, whilst calcium stearate is almost insoluble in water). Without lime in the solution, SO formed a large amount of stable foam which remained intact after 5 minutes. When lime was incorporated, the amount of foam was very small, but with high stability. However, CS did not form any foam, either with lime or without it. Table 3 summarises these results.

From these results, sodium oleate could be expected to be better spread than calcium stearate into the mortar volume, thanks to its dissolution in water. CS will tend to form a separate layer because its solubility is virtually zero. Nevertheless, sodium oleate showed no compatibility with the lime, because the foam volume underwent a dramatic drop when lime was added. These results for SO can be related to those reported by Atahan and co-workers [22] on SO solutions modified by cement addition: they stated no likelihood of compatibility between the pure SO and cement used. In the current study, with solutions modified by lime addition, the results are very similar. This could be due to the high calcium ion concentration, because $\mathrm{Ca}^{2+}$ ions are able to react with the oleate forming a precipitant, calcium oleate, with negligible solubility in water [40]. This fact prevents oleate molecules from generating and stabilizing foam. The very scarce amount of remaining foam is formed by the residual concentration of sodium oleate. 
UV-measurements were carried out in order to evaluate additive adsorption on lime particles. Table 4 shows the absorbance values of SO and CS solutions, as well as SO and CS solutions with slaked lime added. It can be noticed that, as expected, CS did not dissolve any amount in water, confirming its worse behaviour in the foam test. However, the SO solution showed an absorbance of 0.24 at $270 \mathrm{~nm}$. When lime was added, the absorbance band disappeared, thus suggesting an adsorption effect of SO on lime particles. Apart from the previously discussed repercussions on the foam formation, this adsorption on lime particles would make it possible to distribute the sodium oleate uniformly into the mortar mass when used.

\subsection{Rheological properties}

\subsubsection{Amount of required water and consistency}

In the present study, the slump value was previously set, so Table 1 shows the amount of water that the addition of the two admixtures requires to reach that value. When additives were used at a low dosage, the amount of water was quite similar to that for the reference mortar. Nevertheless, in mixtures with a high dose of additive, a large amount of water was needed in order to achieve the set slump. These results are in agreement with those obtained in lime mortars by Seabra et al. [1], who observed that the presence of an AEA led to a slight decrease in slump values. It was evident that in the aforementioned paper, the mixing water was set, so slump values changed. This behaviour may be explained by the fact that when a high dose is incorporated, the

mixture increases in small particles with a high specific surface area, thus demanding a large amount of water. 


\subsubsection{Air content}

Air content rose when sodium oleate or calcium stearate were added, as Table 5 shows. The percentages of entrained air are comparable to those previously obtained in cement mortars or concrete [25, 41-43]. However, SO showed larger percentages of entrained air than CS, which may be due to the solubility behaviour of CS and its lower compatibility with lime solutions.

The dosage of the additive turned out to be unimportant. To a certain extent, this result was unexpected, because it might have been considered that the higher the amount of additive, the larger the entrained air. However, it has been stated that when some air entraining agents - surfactants - are used beyond a certain dosage, they no longer contribute to improve certain properties of the mortars (fluidity, mechanical strength), and the air content maintains a constant value, without variations as a function of the dosage [27]. In the cited work, the dosage limit was $4.10^{-3} \mathrm{wt} \%$ of the cement weight: taking into account the fact that, in the current study, the lowest dosage was $0.28 \%$ of the lime weight, it can probably be assumed that both dosages of additives employed went beyond that limit.

On the other hand, the observed effectiveness of both admixtures as air-entraining agents could seem contradictory when compared with the total incompatibility of calcium stearate and the rather limited one of sodium oleate with lime, tested through the foam index test (4.1). The presence of calcium carbonate in mortar (as main component of the aggregate) could explain this behaviour. As reported by Külaots et al. 
[40] finely divided calcium carbonate would be able to adsorb the AEA's (anionic surfactants) on its surface, producing stable foam. It seems to be clear that a larger amount of undissolved, solid particles of calcium carbonate with a large available surface, leads to a more stable foam. Regarding this issue, the lack of foam when each additive was mixed with lime and water is perfectly compatible with the air-entrained data in mortars in the current study. The mortars contain a limestone aggregate. From the particle size distribution (Figure 2), the presence of small calcium carbonate particles where admixtures would have been adsorbed can be inferred.

\subsubsection{Water-retention capacity}

This property was assumed not to change with the incorporation of the tested additives, so it was measured in order to study any possible secondary effect. As Table 5 shows, water-retention capacity was high for all the mortars, as lime is itself a very retentive material [44]. The addition of SO or CS did not change this property to a considerable extent.

\subsubsection{Setting time}

As was expected, this property depended directly on the amount of incorporated mixing water. When a large amount of water was added, the paste remained fresh for longer, thus prolonging the setting time. Mortars SO-1 and CS-1 showed a very similar setting time to the reference material, while SO-2 and CS-2 samples proved to have an extremely high one. Only the addition of sodium oleate at a low dosage improved the material in comparison with the reference mortar. 


\subsubsection{Evolution on supports}

Figure 4 shows the appearance of the mortar's layers one day after their application on bricks. The selected bricks had a very high water-absorption coefficient, in order to accelerate the evolution of mortars.

Although the water-retention capacity was very similar for the five mortars, their behaviour when applied on bricks changed dramatically depending on the nature and the amount of additive. The reference mortar showed a large amount of macroscopic fissures, produced because of the high water absorption coefficient of brick. SO-1 and CS-1 mortars had exactly the same appearance, so a low dosage of the additives neither improved nor worsened the crack formation process. However, a high dosage of both water repellent agents affected the result to a considerable extent, which could be related to the greater amount of water required during their preparation. SO-2 sample was found to have good behaviour, with only a few cracks, maybe because the high mixing water allowed the mortar to keep enough water in spite of the brick's absorption. CS-2 mortar proved to have genuinely low adherence, which might put its application as a rendering at risk.

\subsection{Hardened mortar properties}

\subsubsection{Density}


As can be seen in Table 6, density did not change greatly with the use of additives. Both SO and CS admixtures gave rise to a decrease in the density values, and the higher the dosage the more important was the effect. As previously reported, especially SO but also CS anionic surfactants were proved to be AEAs in cement mortars or concrete [2225]. The results obtained in the present study concerning air content in lime mortars are consistent with this behaviour. Air entrained voids may provide an explanation for the density values, taking into account the enhanced effectiveness of SO, as was expected from the foam index test, UV absorbance measurements and air content values.

\subsubsection{Shrinkage}

With regard to shrinkage coefficients (Table 6), the very slight differences in length changes between the different mortars (values expressed as millimetres of variation per $1 \mathrm{~m}$ ) could be considered negligible. As was expected in lime mortars, shrinkage values were notable [45].

\subsubsection{Water absorption capacity through capillarity}

Water absorption is an extremely important property for mortars, as they are usually exposed to environmental phenomena - such as rain - or in contact with elements that could be wet (soil). As a consequence, an untreated mortar could become damaged and cause water movement inside the building structure, thus affecting and damaging other materials such as stones, through efflorescence phenomena [9]. 
SO and CS are supposed considerably to decrease the water absorption through capillarity, hence their commercial distribution as water-repellent agents. As Table 6 shows, both additives were effective in decreasing water-absorption through capillarity, especially when used in high dosage. It was clearly seen that SO is better for this purpose than CS, as it achieved extremely low absorption when used at a low dosage and almost negligible absorption when used at a high dosage.

The different behaviour of these additives may be related to the discussion reported in 4.1. Having the best solubility and adsorption onto lime particles, SO had the best capacity to be spread through the whole volume of the fresh mortar, so that the additive affected the whole mass. However, CS showed a tendency to accumulate on the water surface due to its negligible solubility. It can thus be supposed that the additive was only effective on the surface area of the hardened mortar, leading to a moderate reduction in the water absorption through capillarity.

Regarding the behaviour of capillarity reduction, as was stated in the Introduction to the present paper, the mechanism from which the drop in capillarity takes place has not yet been elucidated. A previous study reported the formation of a hydrophobic film which divides the whole system of the mortar into small districts, choking up or even fully sealing most of the pores. This would be the usual mechanism for water-repelling agents of a polymeric nature [20]. Other papers dealing with anionic surfactant addition in a cement matrix have discussed the formation of isolated air micro-bubbles, which would be the usual mechanism for an air-entraining agent $[24,27]$. As was discussed in 4.3.1, the results of air content and density values of the studied mortars were consistent with the air entraining action of SO and CS. Before performing microstructural analysis, 
several possibilities may be proposed: i) air bubbles might block the capillary pores, and hence preventing them from absorbing water [46]; ii) anionic surfactants inside pores might smooth their inner surface, modifying the water adsorption ability by the hydrophobic part of the surfactant [20]; iii) the simultaneous action of both factors could also cut off capillary function.

\subsubsection{Water vapour permeability}

In the case of repair work, but also in single-coat applications, mortars should have an acceptable vapour permeability level, to allow water vapour to pass from the inside of the building to the outside and evaporate, avoiding water retention and condensation in the material, as well as reducing the transport of damaging ions in the pore structure $[19,47]$.

The permeability coefficient expresses the difficulty that water vapour molecules find when trying to pass through a mortar, so the lower the coefficient, the higher the permeability.

It can be seen from Table 6 that SO increased vapour permeability, and the effect was more important for the high dosage. CS only showed a rise in this property when used at a high dosage.

When we compare these results with water-absorption capillarity data, we must observe that water vapour molecules are much smaller than water drops, so some micropores could be enough to allow water vapour to pass and evaporate but not to absorb liquid 
water. Therefore, as discussed in previous section, anionic surfactants could change the pore size distribution in the mortar in such a way that the smallest ones remain interconnected and enable vapour permeability, but are not large enough to absorb water through capillarity. It could be said that surfactants decrease the number of large pores and increase the number of micropores [27]. This possibility would be compatible with the suggested blockage of the capillary pore system by air bubbles [46].

\subsubsection{Mechanical strengths}

Figure 5 shows the evolution of compressive strength over time. All the tested materials achieved a final strength value comparable to that of the reference mortar, so the addition of $\mathrm{SO}$ or $\mathrm{CS}$ in the dosages of the present work was not detrimental to mechanical behaviour, even though air content and mixing water increased. Furthermore, all of them showed an additional advantage: their compressive strength at 28 days was higher than the reference one. Both SO and CS, when used at a high dosage, achieved their maximum strength values from the first steps of their hardening processes onwards, which could mean an improvement of these lime mortars.

\subsubsection{Pore structure and microstructure}

Figure 6 shows the results obtained for the five studied mortars after 91 days of curing. All of them showed a main peak - almost unimodal distribution - corresponding to $1 \mu \mathrm{m}$ diameter pores, which was in accordance with previous work on lime-based mortars [9, 48, 49]. The addition of SO and CS led to a reduction in the percentage of the small peaks related to larger pores (diameters from $100 \mu \mathrm{m}$ to $10 \mu \mathrm{m}$ ) and to an increase in the 
volume of intruded mercury at the main peak. This fact also reflected previously reported data [27]. Furthermore, all the mixtures containing an additive slightly shifted this main peak towards lower values. These results mean that the presence of SO or CS contributed to block the larger pores and to fill to some extent the smaller ones, producing a more uniform pore size distribution characterized by a lower pore diameter.

This pore size distribution, with lower porosity at larger sizes, can also explain two facts: i) the good results in compressive strength tests, because in spite of the total porosity increase due to the large air content, the decrease in the average pore size was reported to be beneficial to compressive strength when AEAs were added [27]; ii) the reduction of water absorption through capillarity by air bubbles that might cut off the capillary network, giving rise to a decrease in larger pores.

Microstructural analysis brought considerable differences between the tested mortars to light. In the SO-2 sample, a large number of micro-air bubbles well distributed through the material were observed. Most of them were the same size - approximately $50 \mu \mathrm{m}$ in diameter - but some bigger ones $-200 \mu \mathrm{m}$ in diameter - were also detected. This fact is consistent with previous results obtained in cement mortars [27], when sodium oleate was used as an air-entraining agent. Furthermore, some salt deposits were found, and elemental analysis by means of EDS revealed their high carbon content, implying that they are organic compounds, thought to be calcium oleate sediments. Some of these deposits were seen within the calcite matrix, but others were found to belong to the shell of air voids. These latter accumulations were probably formed because of the bipolar nature of the oleate molecule that allowed it to be adsorbed and concentrate in the airpaste interface, stabilizing the air-voids [27]. SO-1 mortars showed substantially fewer 
bubbles and deposits than SO-2 mortars, in accordance with their lower dosage of sodium oleate.

CS-2 also showed air bubbles and deposits of calcium stearate. Nevertheless, the amount of air bubbles was somewhat lower and the average diameter of voids was considerably larger - from $100 \mu \mathrm{m}$ to $700 \mu \mathrm{m}$. In addition, the quantity of salt deposits was substantially higher, which could be related to the aforementioned low solubility of this additive in water, and which confirms its poor dispersion, giving rise to an accumulation in the mixture and reduced effectiveness. Figure 7 shows the air voids and sediments described.

To sum up, having a bipolar nature (hydrophobic and hydrophilic parts) CS and SO were able to be adsorbed and concentrate in the air-paste interface, stabilizing the airvoids, thus showing an air-entraining action (Table 5). Although CS showed water insolubility and SO could form calcium precipitants, such behaviour reduced but did not cancel the air-entraining ability, matching previous results in cement materials [22]. The distribution of the admixtures could be improved by the presence of finely divided calcium carbonate that would be able to adsorb anionic surfactants on its surface [40].

It can be confirmed that the action mechanism of SO and CS consisted of incorporating air bubbles into the whole mass of the mortar, leading to a blockage of pores and, therefore, preventing water intake.

SO turned out to be better in air-entraining action as well as in capillarity reduction (waterproofing) owing to its larger solubility and adsorption capacity on lime particles. 
These last fact allowed SO, by spreading out into the whole mass of the mortar, to stabilize more air-voids.

\subsubsection{Durability: Freezing-thawing cycles}

Table 7 shows the degree of alteration of the mortars after they were subjected to several freezing-thawing cycles. Not all the prepared mortars lasted long enough to be tested at the set times, as can be seen in Figure 8.

The reference material was completely destroyed after 6 freezing-thawing cycles, after showing signs of deterioration from the first steps. Both additives improved the durability of the material. SO-2 mortar managed to complete 14 freezing-thawing cycles without any sign of deterioration. CS-2 mortar showed better performance than the reference one, lasting two cycles longer, but proved considerably worse than SO-2 samples.

The better behaviour of treated mortars is related to the effectiveness of the additives as water repellents (reducing the intake of water during the immersion) as well as their role as air-entraining agents, because air voids shown by SEM examination provide an escape boundary to which water can flow and freeze. The volume expansion of this last process takes place without generating pressures large enough to damage the mortar [23].

The difference between SO and CS mortars is due to the greater amount of air bubbles stabilized by SO, as the SEM results show. Compressive strength results after freezing- 
thawing cycles (Figure 9) confirm the excellent behaviour of SO lime-based mortars, with only a slight drop in strength after 14 cycles.

\section{Conclusions}

Sodium oleate and calcium stearate were tested as additives for lime-based mortars and different properties were studied in a fresh state and also in hardened material, in order to test their efficiency. Sodium oleate clearly improved the behaviour of lime-based mortars when used at $0.5 \%$ of the total dried mortar weight. The improvement was especially remarkable in terms of water absorption through capillarity, which was reduced, and enhanced durability of the material towards freezing-thawing cycles, without being detrimental for mechanical strength. Furthermore, maximum compressive strengths were reached in a shorter period of time. The tested SO-lime mortars also show a smaller number of cracks when their evolution on a support was subjected to monitoring.

An action mechanism based on the air-entraining ability of anionic surfactants (such as SO and CS) has been shown to be responsible for this behaviour. These admixtures cause the formation of air voids which block the capillary net and reduce the water intake. In addition, if freezing takes place, water expansion occurs in the bubbles without damaging the mortar structure.

Although calcium stearate also improved lime-based mortars, it has been shown to be considerably less effective than sodium oleate, probably due to its insolubility in water 
and its poorer dispersion into the mass of the mortar, which leads to the formation of a lower number of air voids.

\section{Acknowledgements}

The authors want to thank CTH Navarra and Fernando Moreno (Calinsa S.A. Navarra) for the material supplied. We are also grateful to Dr. Jon Joseba Echeberria for his help with SEM and to the staff in Laboratorio de Edificación (Universidad de Navarra) for the material support and invaluable help. 


\section{References}

[1] M.P. Seabra, H. Paiva, J.A. Labrincha, V.M. Ferreira, Admixtures effect on fresh state properties of aerial lime based mortars, Constr Build Mater 23 (2009) 1147-1153.

[2] J. Lanas, J.I. Alvarez, Masonry repair lime-based mortars: Factors affecting the mechanical behavior, Cem Concr Res 33(2003) 1867-1876.

[3] M.R. Veiga, A. Velosa, A. Magalhaes, Experimental applications of mortars with puzzolanic additions: Characterization and performance evaluation, Constr Build Mater 23 (1) (2009) 318-327.

[4] M.J. Mosquera, B. Silva, B. Prieto, E. Ruiz-Herrera, Addition of cement to limebased mortars: Effect on pore structure and vapor transport, Cem Concr Res 36 (2006) $1635-1642$.

[5] R. Malinowski, Ancient Mortars and Concretes, Durability Aspects, Mortars, Cements and Grouts Used in Conservation of Historic Buildings, Proceedings of the Symposium, ICCROM, Rome, 1981, 341-350.

[6] C. Rodríguez-Navarro, E. Hansen, W.S. Ginell W. S., Calcium hydroxide crystal evolution upon aging of lime putty, J Am Ceram Soc 81 (1998) 3032-3034.

[7] C. Rodriguez-Navarro, O. Cazalla, K. Elert, E. Sebastian, Liesegang Pattern Development in Carbonating Traditional Lime Mortars, Proc Roy Soc London A Math 458 (2002) 2261-2273.

[8] C. Atzeni, A. Farci, D. Floris, P. Meloni, Effect of Aging on Rheological Properties of Lime Putty, J Am Ceram Soc 87 (9) (2004) 1764-1766.

[9] M. Arandigoyen, J.L. Perez Bernal, M.A. Bello Lopez, J.I. Alvarez, Lime-pastes with different kneading water: Pore structure and capillary porosity, Appl Surf Sci 252 (2005) 1449-1459.

[10] M.P. Seabra, J.A. Labrincha, V.M. Ferreira, Rheological behaviour of hydraulic lime-based mortars, J Euro Ceram Soc 27 (2007) 1735-1741.

[11] R.M. Lawrence, T.J. Mays, S.P. Rigby, P. Walker, D. D’Ayala, Effects of carbonation on the pore structure of non-hydraulic lime mortars, Cem Concr Res 37 (2007) 1059-1069.

[12] A. El-Turki, R.J. Ball, G.C. Allen, The influence of relative humidity on structural and chemical changes during carbonation of hydraulic lime, Cem Concr Res 37 (2007) 1233-1240.

[13] V.A. Ghio, The rheology of fresh cement paste containing polysaccharide gums, Cem Concr Res 2 (1994) 243-249. 
[14] M. Sonebi, Rheological properties of grouts with viscosity modifying agents as diutan gum and welan gum incorporating pulverized fly ash, Cem Concr Res 36 (2006) 1609-1618.

[15] P.C. Mishra, V.K. Singh, K.K. Narang, N.K. Singh, Effect of carboxymethylcellulose on the properties of cement, Mat Eng A 357 (2003) 13-19.

[16] N.K. Singh, P.C. Mishra, V.K. Singh, K.K. Narang, Effects of hydroxyethyl cellulose and oxalic acid on the properties of cement, Cem Concr Res 33 (2003) 13191329.

[17] G. Cultrone, E. Sebastian, M. Ortega Huertas, Forced and natural carbonation of lime-based mortars with and without additives: Mineralogical and textural changes, Cem Concr Res 35 (2005) 2278-2289.

[18] C. Fortes-Revilla, S. Martinez-Ramirez, M.T. Blanco-Varela, Modelling of slaked lime-metakaolin mortar engineering characteristics in terms of process variables, Cem Concr Compos 28 (2006) 458-467.

[19] P. Maravelaki-Kalaitzaki, Hydraulic lime mortars with siloxane for waterproofing historic masonry, Cem Concr Res 37 (2007) 283-290.

[20] Z. Lu, X. Zhou, The waterproofing characteristics of polymer sodium carboxiymethyl-cellulose, Cem Concr Res 30 (2000) 227-231.

[21] Z. Lu, X. Zhou, J. Zhang, Study on the performance of a new type of waterrepellent admixture for cement mortar, Cem Concr Res 34 (2004) 2015-2019.

[22] H.N. Atahan, C. Carlos Jr., S. Chae, P.J.M. Monteiro, J. Bastacky, The morphology of entrained air voids in hardened cement paste generated with different anionic surfactants, Cem Concr Compos 30 (2008) 566-575.

[23] S. Chatterji, Freezing of air-entrained cement-based materials and specific actions of air-entraining agents, Cem Concr Compos 25 (2003) 759-765.

[24] Y. Shen, M.L. Longo, R.L. Powell, Stability and rheological behaviour of concentrated monodisperse food emulsifier coated microbubble suspensions, J Colloid Interf Sci 327 (2008) 204-210.

[25] D.J. Corr, J. Lebourgeois, P.J.M. Monteiro, S.J. Bastacky, E.M. Gartner, Air voids morphology in fresh cement pastes, Cem Concr Res 32 (2002) 1025-1031.

[26] Process for waterproofing gypsum materials, US Patent 5702828, December 1997.

[27] X. Ouyang, Y. Guo, X. Qiu, The feasibility of synthetic surfactant as an air entraining agent for the cement matrix, Constr Build Mater 22 (2008) 1774-1779.

[28] UNE-EN 459-1, Building lime. Part 1. Definition, specification and conformity criteria (2001). 
[29] J. Lanas, J.L. Perez Bernal, M.A. Bello, J.I. Alvarez, Mechanical properties of masonry repair dolomitic lime-based mortars, Cem Concr Res 36 (5) (2006) 951-960.

[30] A. Garcia Santos, J.Ma. Rincon, M. Romero, R. Talero, Characterization of a polypropylene fibered cement composite using ESEM, FESEM and mechanical testing, Constr Build Mater 19 (2005) 396-403.

[31] UNE-EN1015-3, Methods of test for mortar for masonry. Part 3: Determination of consistence of fresh mortar (by flow table) (2000).

[32] UNE-EN 1015-6, Methods of test for mortar for masonry. Part 6: Determination of bulk density of fresh mortar (1999).

[33] UNE-EN 1015-7, Methods of test for mortar for masonry. Part 7: Determination of air content of fresh mortar (1999).

[34] UNE 83-816-93, Test methods. Mortars. Fresh mortars. Determination of water retentivity (1993).

[35] UNE-EN 1015-9, Methods of test for mortar for masonry. Part 9: Determination of workable life and correction time of fresh mortar (2000).

[36] UNE-EN 1015-18, Methods of test for mortar for masonry. Part 18: Determination of water absorption coefficient due to capillary action of hardened mortar (2003).

[37] UNE-EN 1015-19, Methods of test for mortar for masonry. Part 19: Determination of water vapour permeability of hardened rendering and plastering mortars (1999).

[38] UNE-EN 1015-11, Methods of test for mortar for masonry. Part 11: Determination of flexural and compressive strength of hardened mortar (2000).

[39] J. Lanas, R. Sirera, J.I. Alvarez, Study of the mechanical behavior of masonry repair lime-based mortars cured and exposed under different conditions, Cem Concr Res 36 (5) (2006) 961-970.

[40] I. Külaots, A. Hsu, R.H. Hurt, E.M. Suuberg, Adsorption of surfactants on unburned carbon in fly ash and development of a standardized foam index test, Cem Concr Res 33 (2003) 2091-2099.

[41] A. Benazzouk, O. Douzane, K. Mezreb, M. Queneudec, Physico-mechanical properties of aerated cement composites containing shredded rubber waste, Cem Concr Compos 28 (2006) 650-657.

[42] J. Deja, Freezing and de-icing salt resistance of blast furnace slag concretes, Cem Concr Compos 25 (2003) 357-361.

[43] T. Bakharev, J.G. Sanjayan, Y.B. Cheng, Effect of admixtures on properties of alkali-activated slag concrete, Cem Concr Res 30 (2000) 1367-1374. 
[44] K.M. Green, M.A. Carter, W.D. Hoff, M.A. Wilson, The effects of lime and admixtures on the water-retaining properties of cement mortars, Cem Concr Res 29 (1999) 1743-1747.

[45] F.G. Collins, J.G. Sanjayan, Workability and mechanical properties of alkali activated slag concrete, Cem Concr Res 29 (1999) 455-458.

[46] V. Fernandes, L. Silva, V.M. Ferreira, J.A. Labrincha, Evaluation of mixing and application process parameters of single-coat mortars, Cem Concr Res 35 (2005) 836841.

[47] M.J. Mosquera, D. Benitez, S.H. Perry, Pore structure in mortars applied on restoration. Effect on properties relevant to decay of granite buildings, Cem Concr Res 32 (2002) 1883-1888.

[48] F. Collet, M. Bart, L. Serres, J. Miriel, Porous structure and water vapour sorption of hemp-based materials, Constr Build Mater 22 (2008) 1271-1280.

[49] J. Lanas, J.L. Perez-Bernal, M.A. Bello, J.I. Alvarez Galindo, Mechanical properties of natural hydraulic lime-based mortars, Cem Concr Res 34 (2004) 21912201.

Table 1. Composition of the five different mortars.

\begin{tabular}{l|c|c|c|c|c}
\multirow{2}{*}{ Composition (g) } & \multicolumn{5}{|c}{ Samples } \\
\cline { 2 - 6 } & REF & SO-1 & SO-2 & CS-1 & CS-2 \\
\hline Lime & 341.7 & 341.7 & 341.7 & 341.7 & 341.7 \\
\hline Aggregate & 1286.9 & 1286.9 & 1286.9 & 1286.9 & 1286.9 \\
\hline Sodium oleate & - & 0.98 & 8.16 & - & - \\
\hline Calcium stearate & - & - & - & 0.98 & 8.16 \\
\hline Water & 410 & 400 & 440 & 420 & 440
\end{tabular}

Table 2. Freezing-thawing cycles.

\begin{tabular}{c|c|c|c|c} 
Cycle duration & Steps & Temperature & Water immersion & Time \\
\hline \multirow{2}{*}{48 hours } & Step 1 & Room temperature & Yes & 24 hours \\
\cline { 2 - 5 } & Step 2 & $-10^{\circ} \mathrm{C} \pm 2^{\circ} \mathrm{C}$ & No & 24 hours
\end{tabular}


Table 3. Results for the foam index test.

\begin{tabular}{c|c|c|c} 
& \multicolumn{3}{|c}{ Steps } \\
\hline & Mix with water & Shaking & After 5 minutes \\
\hline SO & Dissolution & $64 \%$ foam & $64 \%$ foam \\
\hline SO+Lime & Dissolution+Lime & $1 \%$ foam & $1 \%$ foam \\
\hline CS & Separate layer & - & - \\
\hline CS+Lime & Separate layer & - & -
\end{tabular}

Table 4. UV-vis absorbance for the different solutions.

\begin{tabular}{c|c|c|c|c}
\multirow{2}{*}{$\begin{array}{c}\text { Absorption } \\
\text { band }\end{array}$} & \multicolumn{4}{|c}{ Absorbance value } \\
\cline { 2 - 5 } & SO & CS \\
\cline { 2 - 5 } & In water & In water+Lime & In water & In water-Lime \\
\hline $270 \mathrm{~nm}$ & 0.24 & 0 & 0 & 0
\end{tabular}

Table 5. Rheological properties of the five mixtures.

\begin{tabular}{c|c|c|c} 
& Air content (\%) & $\begin{array}{c}\text { Setting time } \\
\text { (minutes) }\end{array}$ & $\begin{array}{c}\text { Water retention } \\
\text { capacity (\%) }\end{array}$ \\
\hline REF & 2.8 & 195 & 94.3 \\
\hline SO-1 & 4.2 & 157 & 92.8 \\
\hline SO-2 & 4.2 & 465 & 95.4 \\
\hline CS-1 & 3.7 & 235 & 95.5 \\
\hline CS-2 & 3.4 & 960 & 94.4
\end{tabular}


Table 6. Properties at hardened state.

\begin{tabular}{|c|c|c|c|c|}
\hline & $\begin{array}{l}\text { Density } \\
\text { (g/mL) }\end{array}$ & $\begin{array}{c}\text { Shrinkage } \\
\text { coefficient } \\
(\mathbf{m m} / \mathbf{m})\end{array}$ & $\begin{array}{c}\text { Capillarity } \\
\text { coefficient } \\
\left(\mathrm{kg} / \mathbf{m}^{2} \cdot \mathbf{m i n}^{\mathbf{1} / 2}\right)\end{array}$ & $\begin{array}{c}\text { Permeability } \\
\text { coefficient }\end{array}$ \\
\hline REF & 1.67 & 13.59 & 2.36 & 16.6 \\
\hline SO-1 & 1.61 & 12.60 & 0.58 & 15.3 \\
\hline SO-2 & 1.58 & 15.94 & 0.06 & 14.9 \\
\hline CS-1 & 1.65 & 15.52 & 1.59 & 20.8 \\
\hline CS-2 & 1.62 & 14.01 & 1.40 & 15.7 \\
\hline
\end{tabular}

Table 7. Qualitative evaluation of the mortars after freezing-thawing cycles.

\begin{tabular}{c|c|c|c|c|c}
\multirow{2}{*}{} & \multicolumn{6}{|c}{ Alteration degree } \\
\cline { 2 - 6 } & 1 cycle & 4 cycles & 7 cycles & 10 cycles & 14 cycles \\
\hline REF & 0 & 4 & - & - & - \\
\hline SO-2 & 0 & 0 & 0 & 0 & 0 \\
\hline CS-2 & 0 & 0 & 2 & - & -
\end{tabular}

Equivalences of the alteration degrees:

0 : Without alteration.

1: Slightly altered, some small (thin and short) cracks on the surface of the specimens.

2: Altered, several cracks (like spider's web) and deeper.

3: Very altered, several deep cracks and swelling of the specimen.

4: High degree of alteration, large and deep cracks, large swelling of the specimen including a partial weight loss.

5: Completely altered, the specimen is practically destroyed, only little pieces of it are kept. 


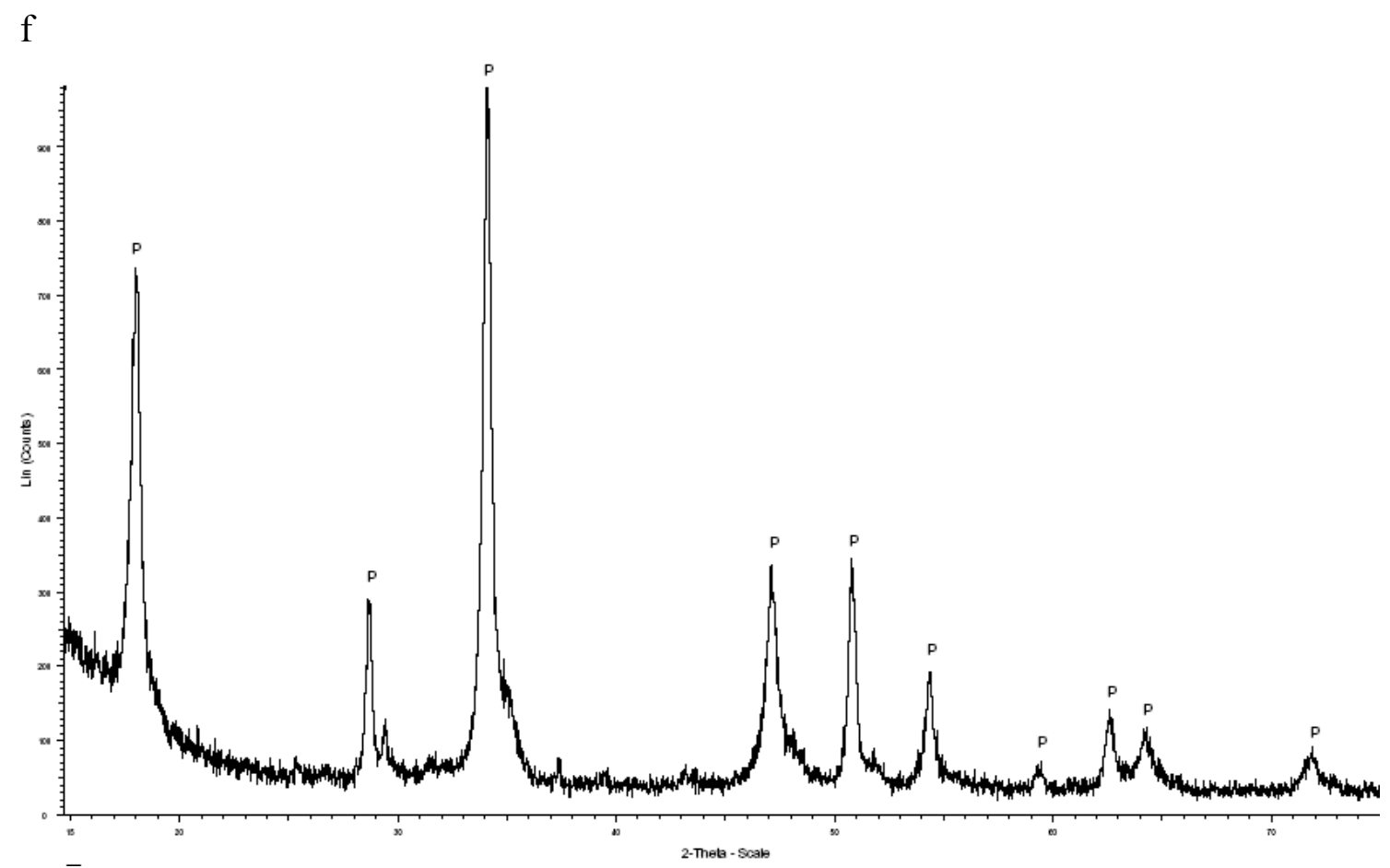

a)

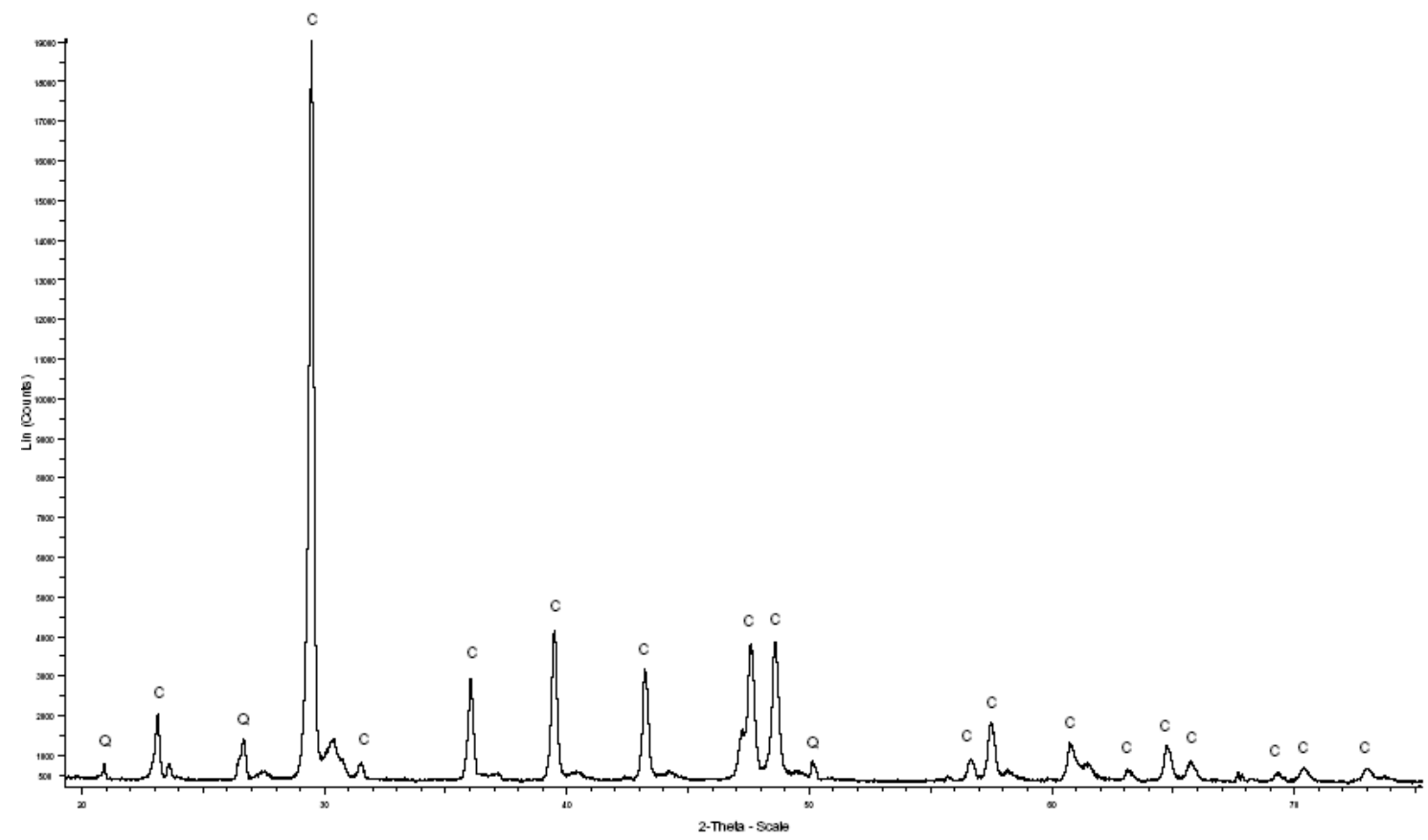

b)

Figure 1. XRD patterns for a) lime and b) aggregate, where P: portlandite; C: calcite; Q: quartz. 


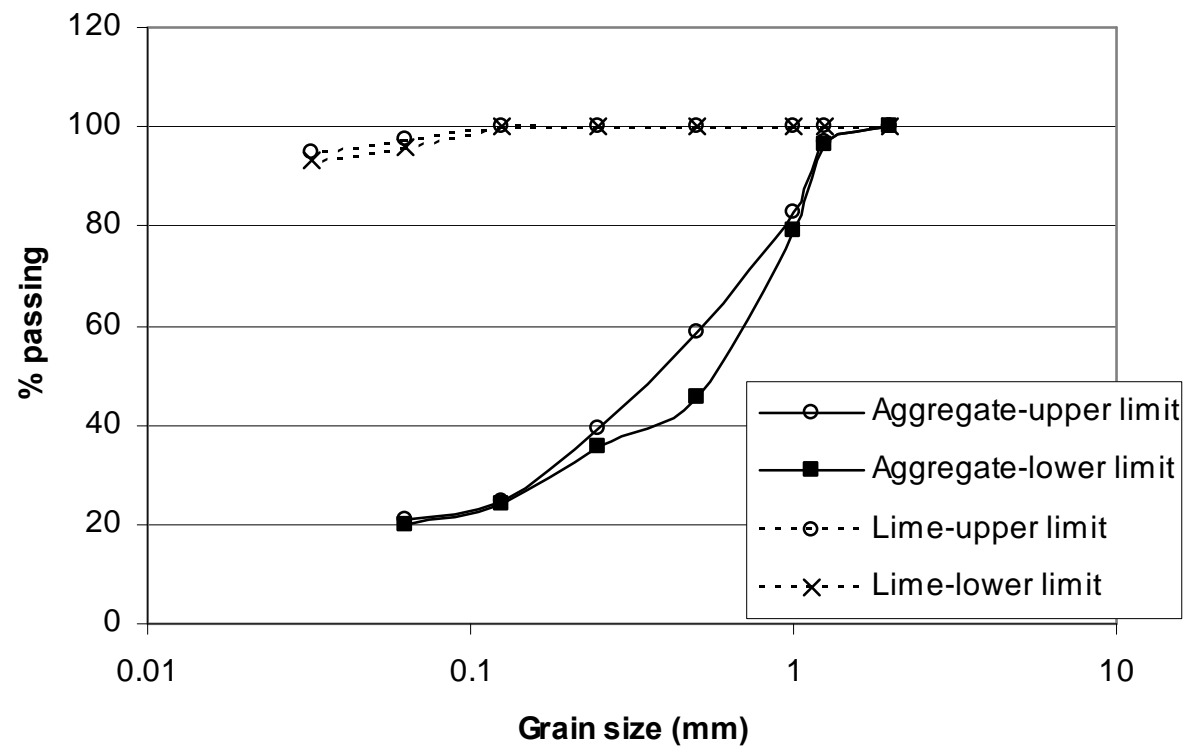

Figure 2. Grain size distribution of lime and aggregate. 


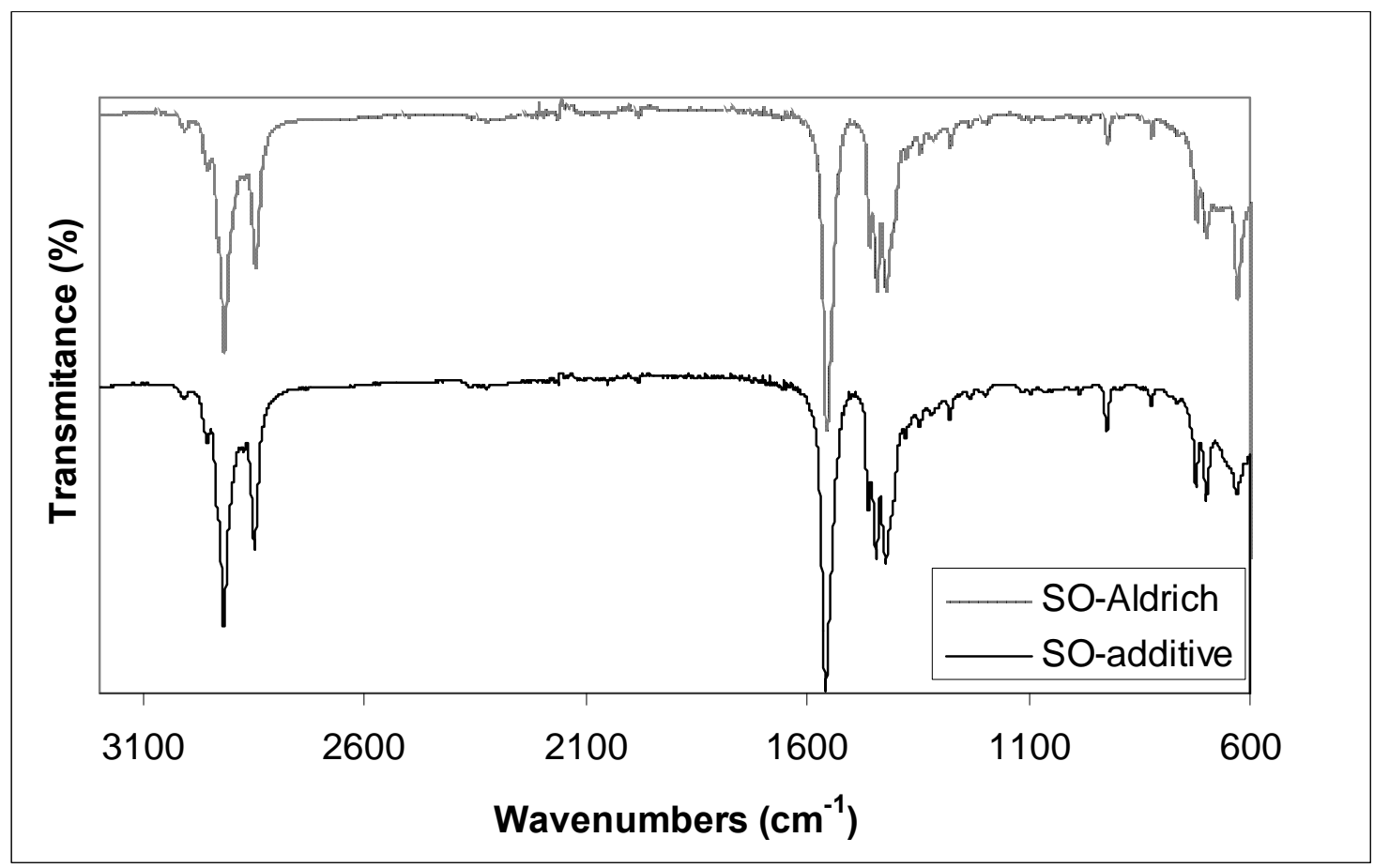

a)

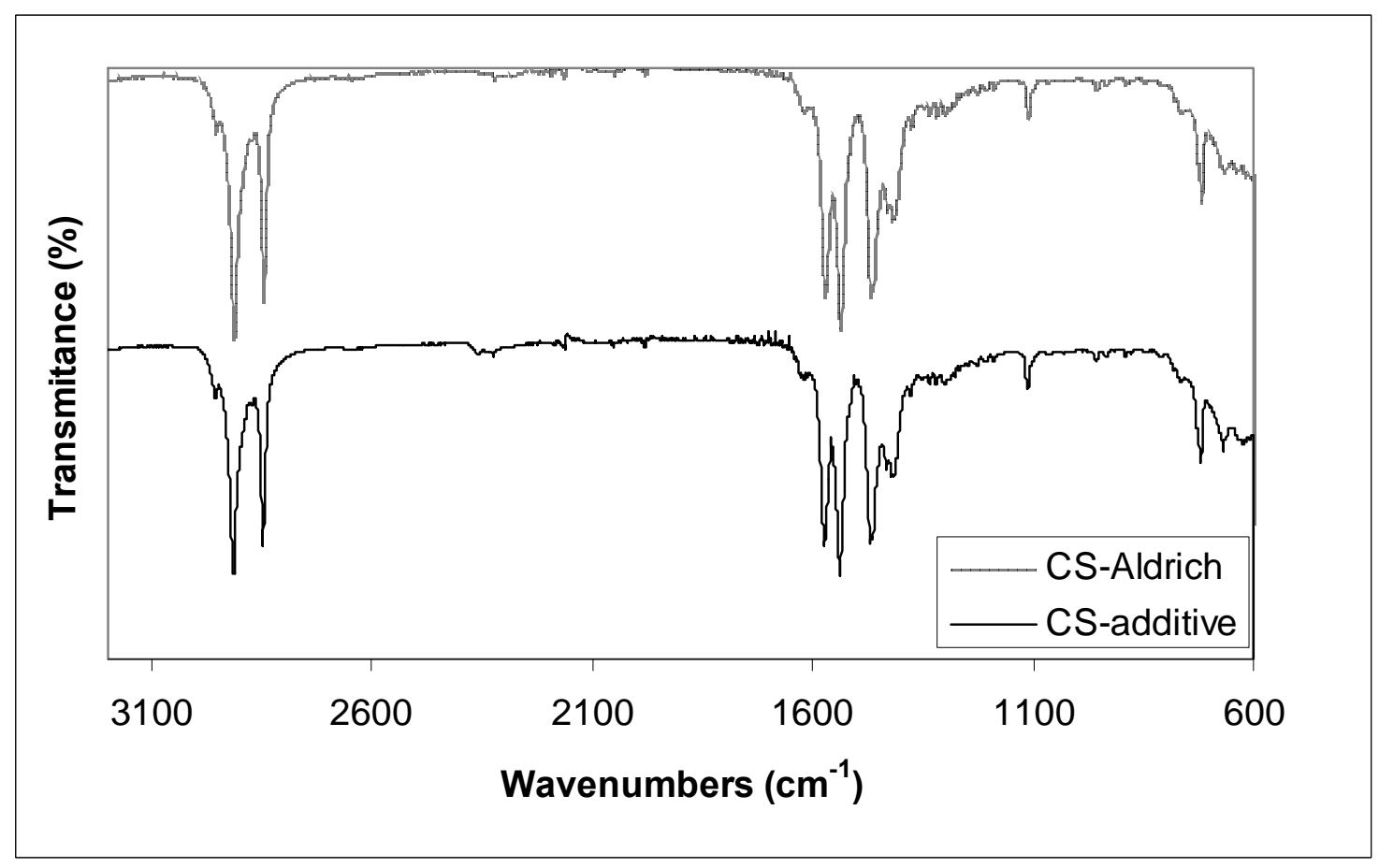

b)

Figure 3. IR spectra of a) pure sodium oleate and additive HISA A $2388 \mathrm{~N}$; b) pure calcium stearate and additive ETP-09. 

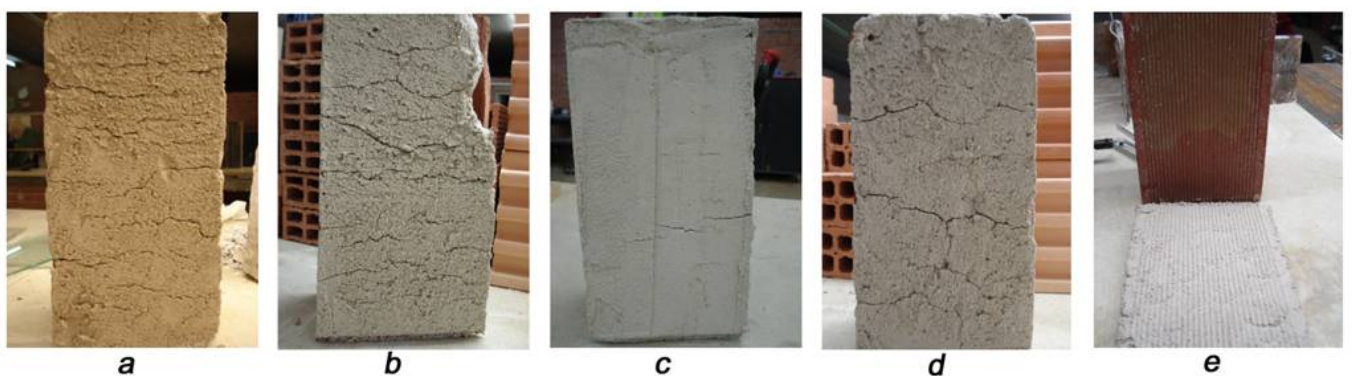

Figure 4. Evolution of mortars on bricks. a) REF; b) SO-1; c) SO-2; d) CS-1; e) CS-2.

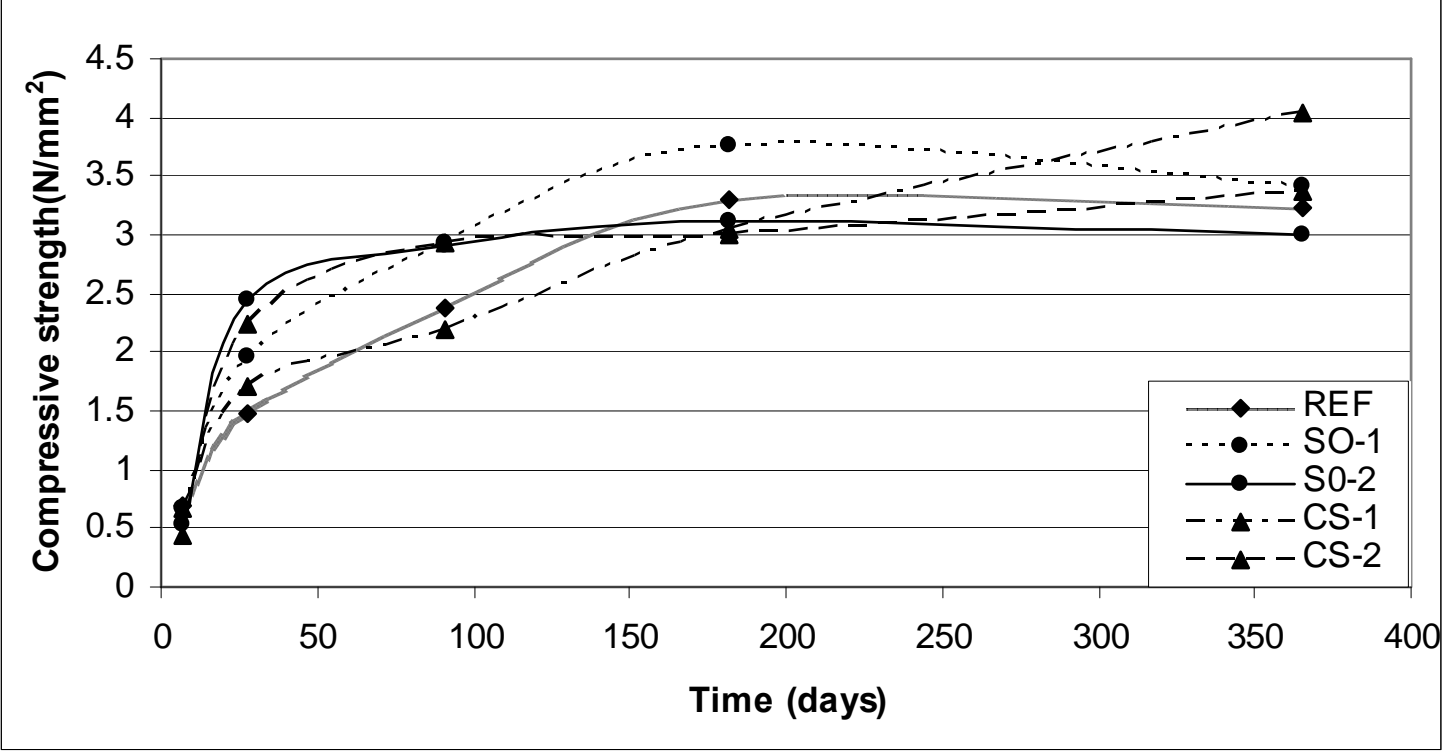

a)

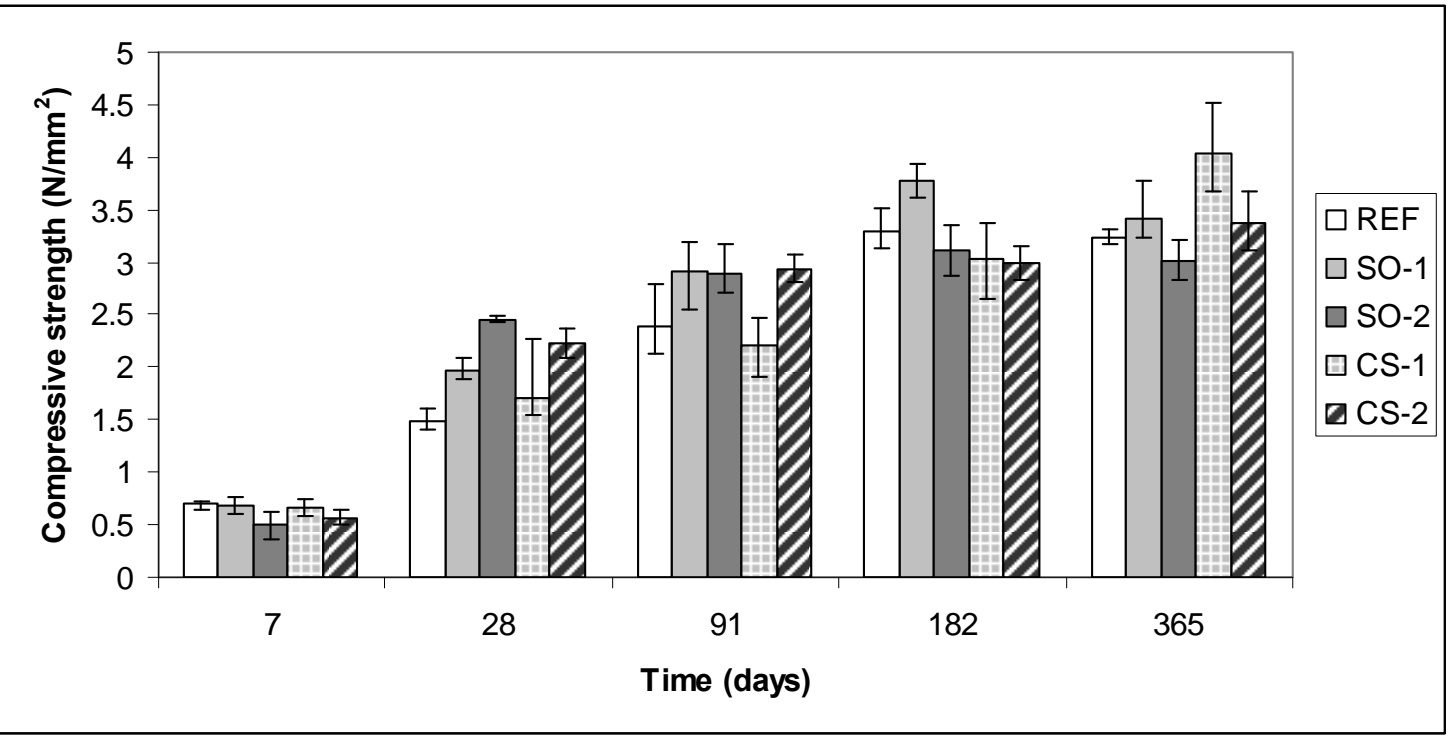

b)

Figure 5. a) Compressive strength vs. time for the tested mortars; b) Compressive strength vs. time showing the error bars. 


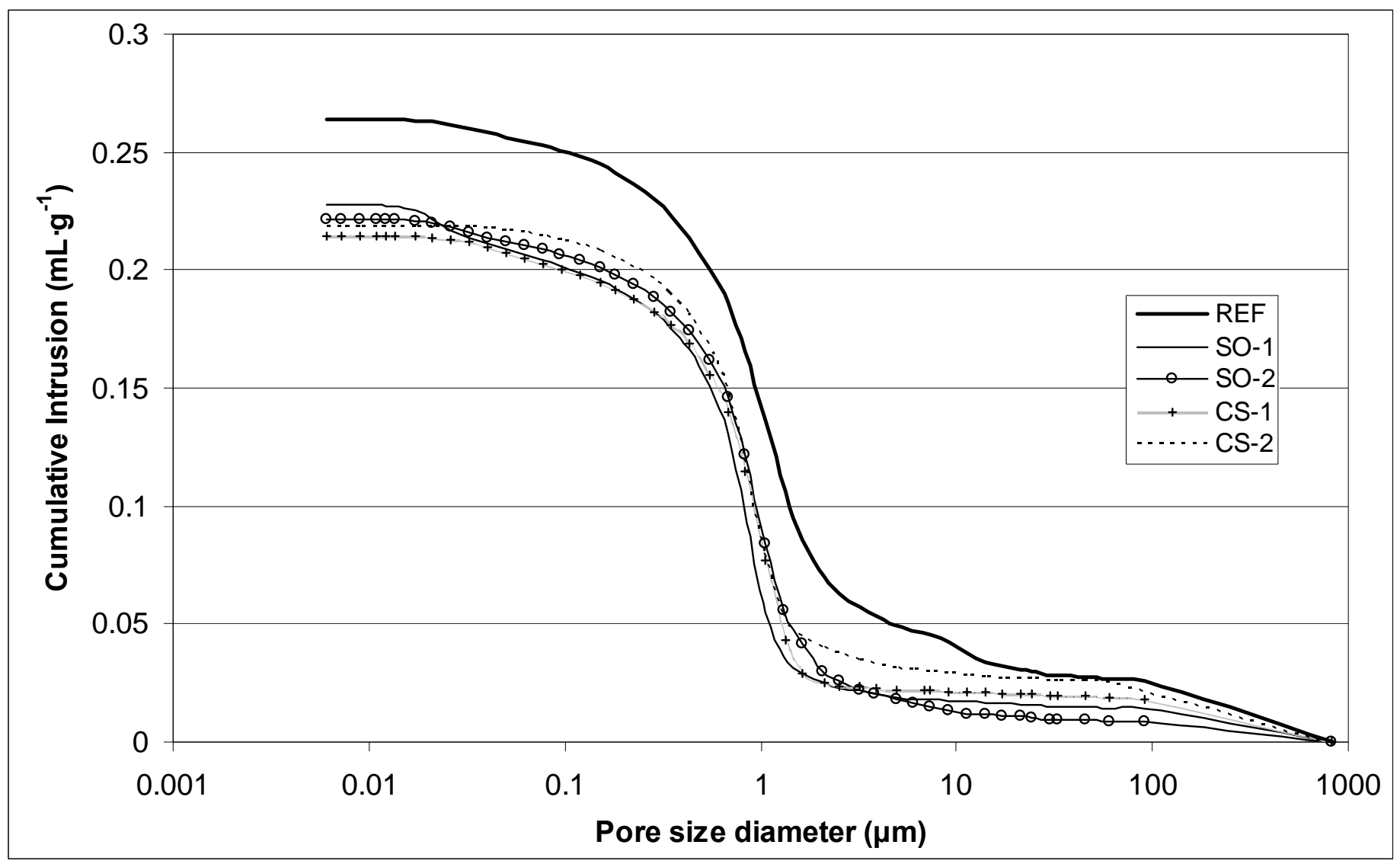

Figure 6. Results from mercury intrusion porosimetry for the five studied mortars. 


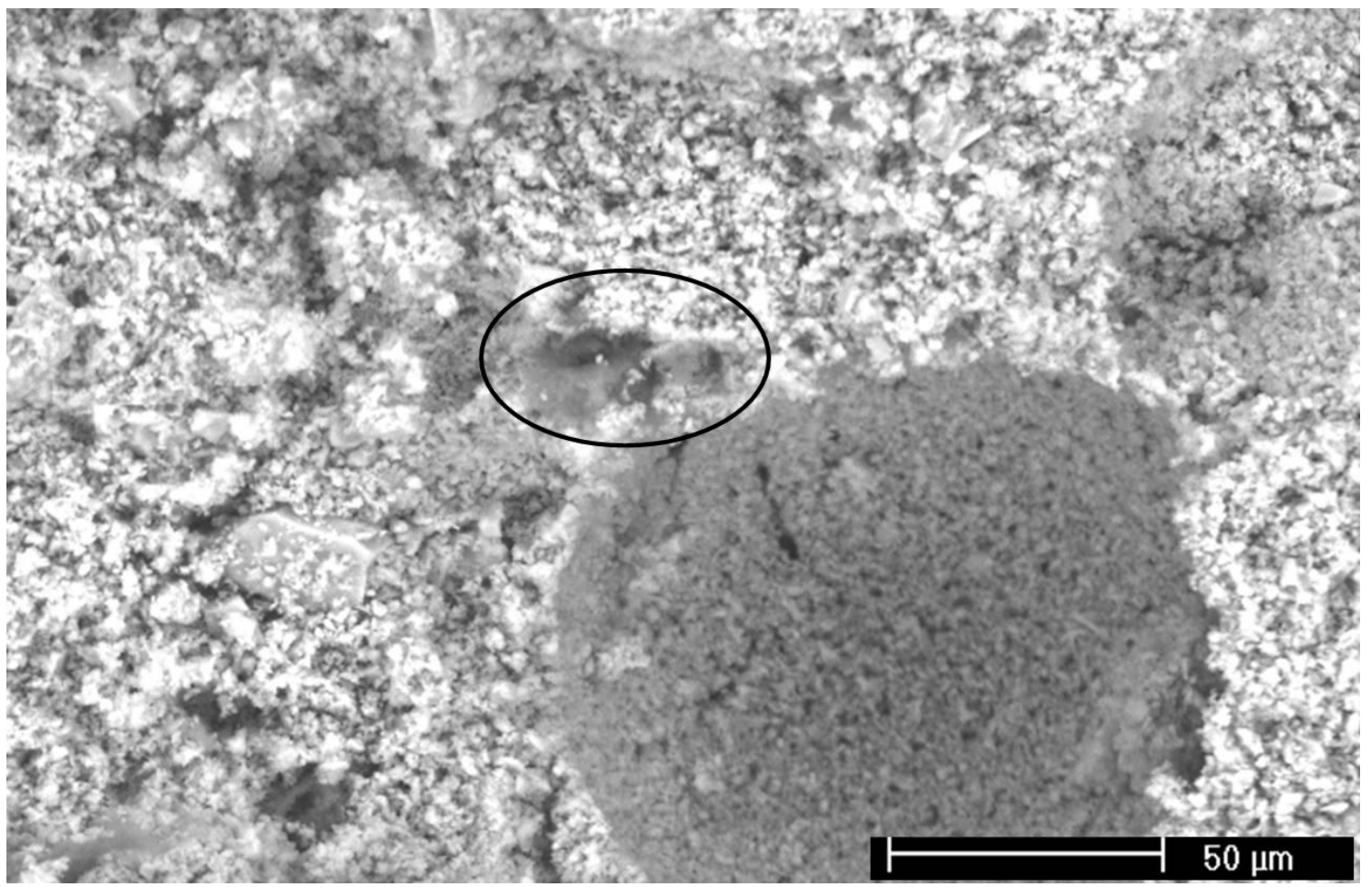

a)

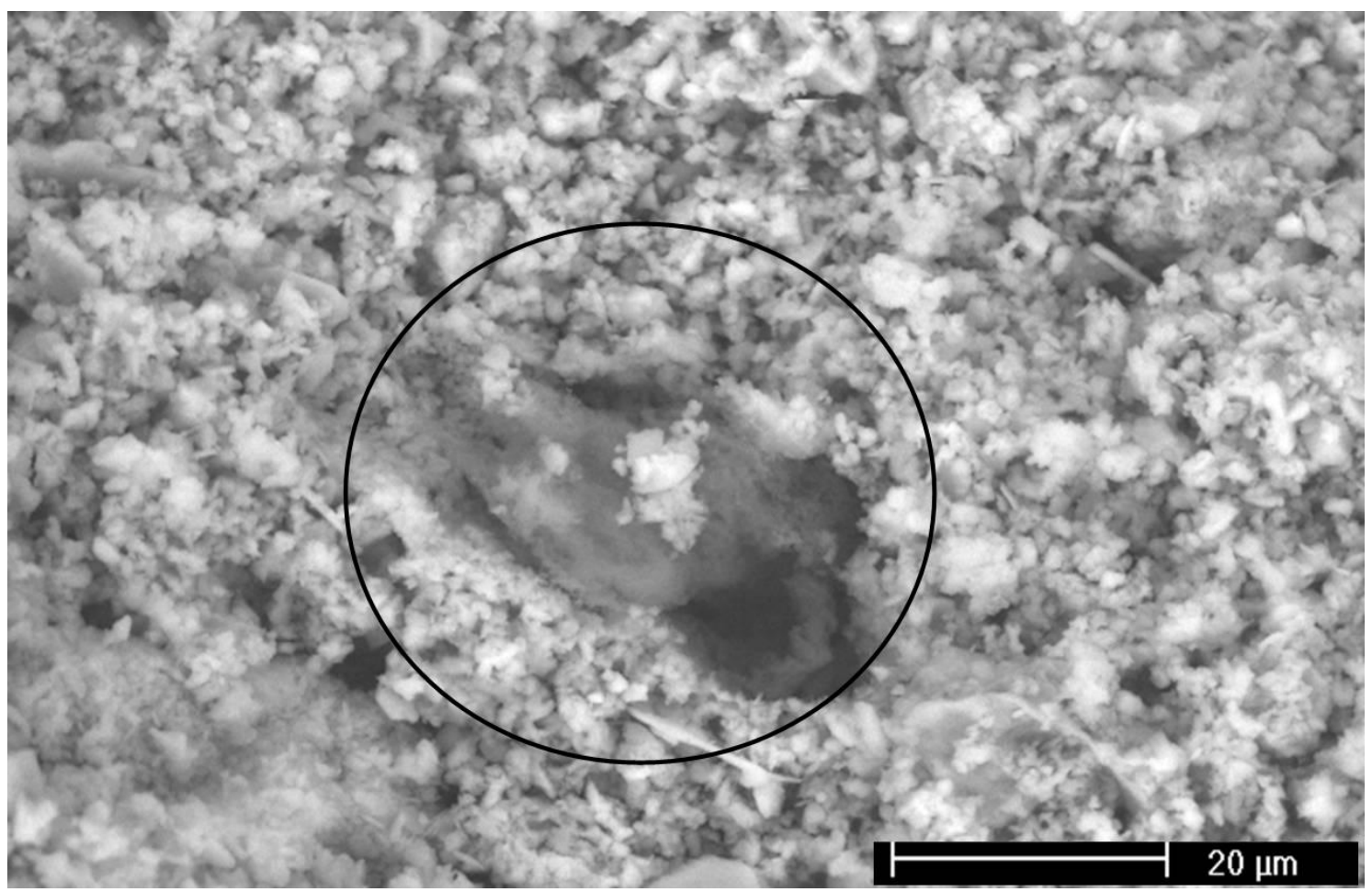

b) 


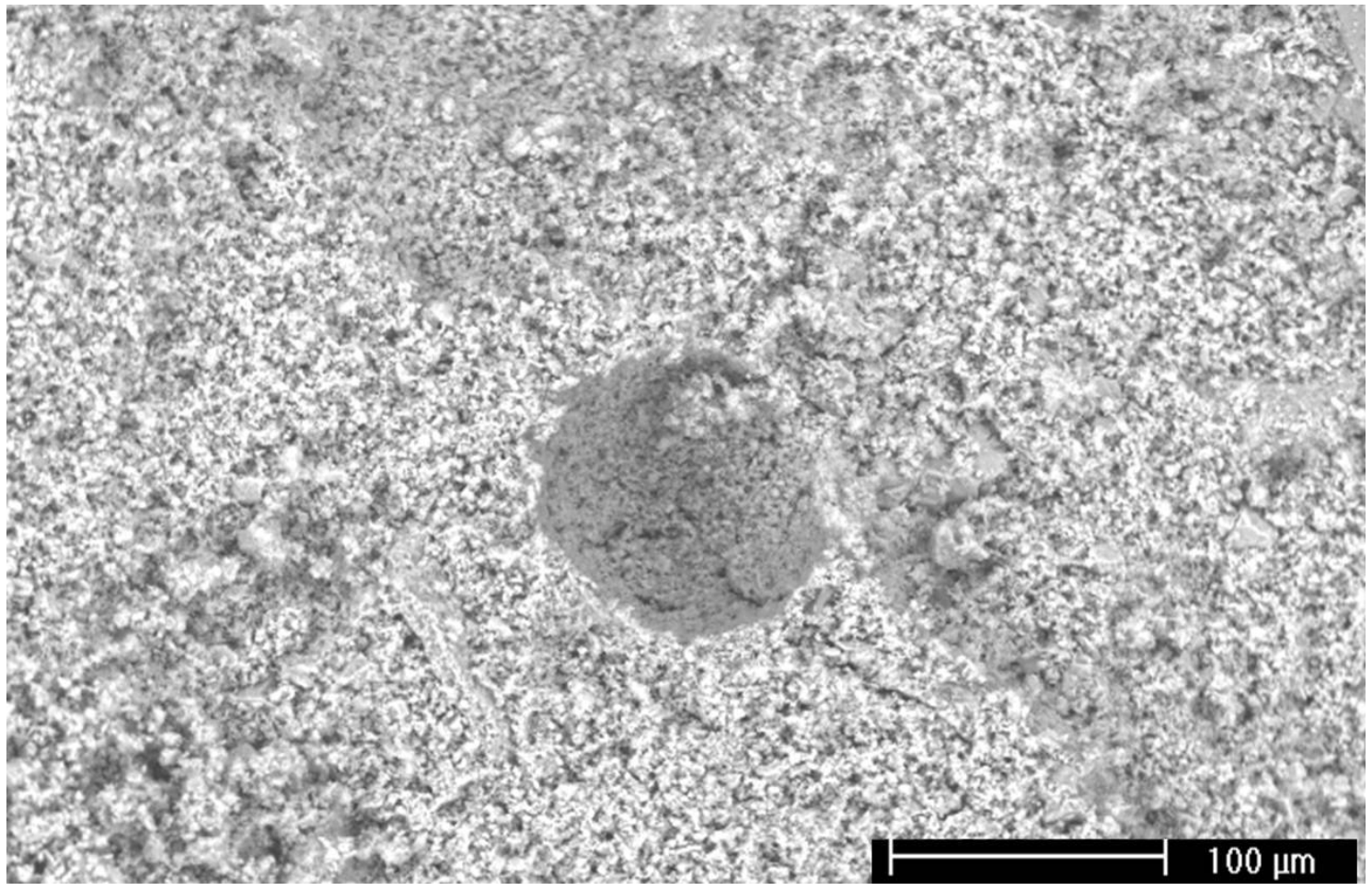

c)

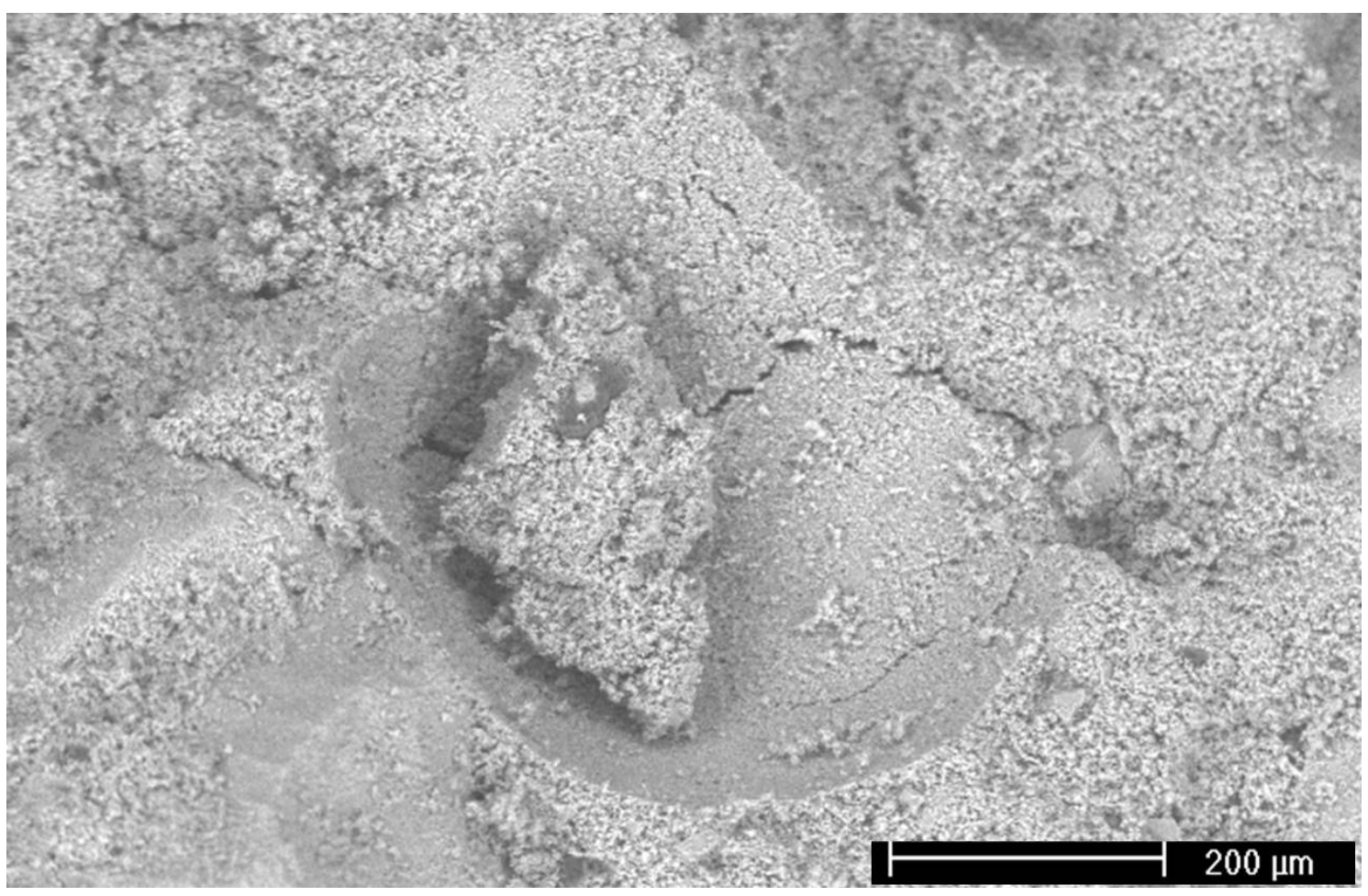

d) 


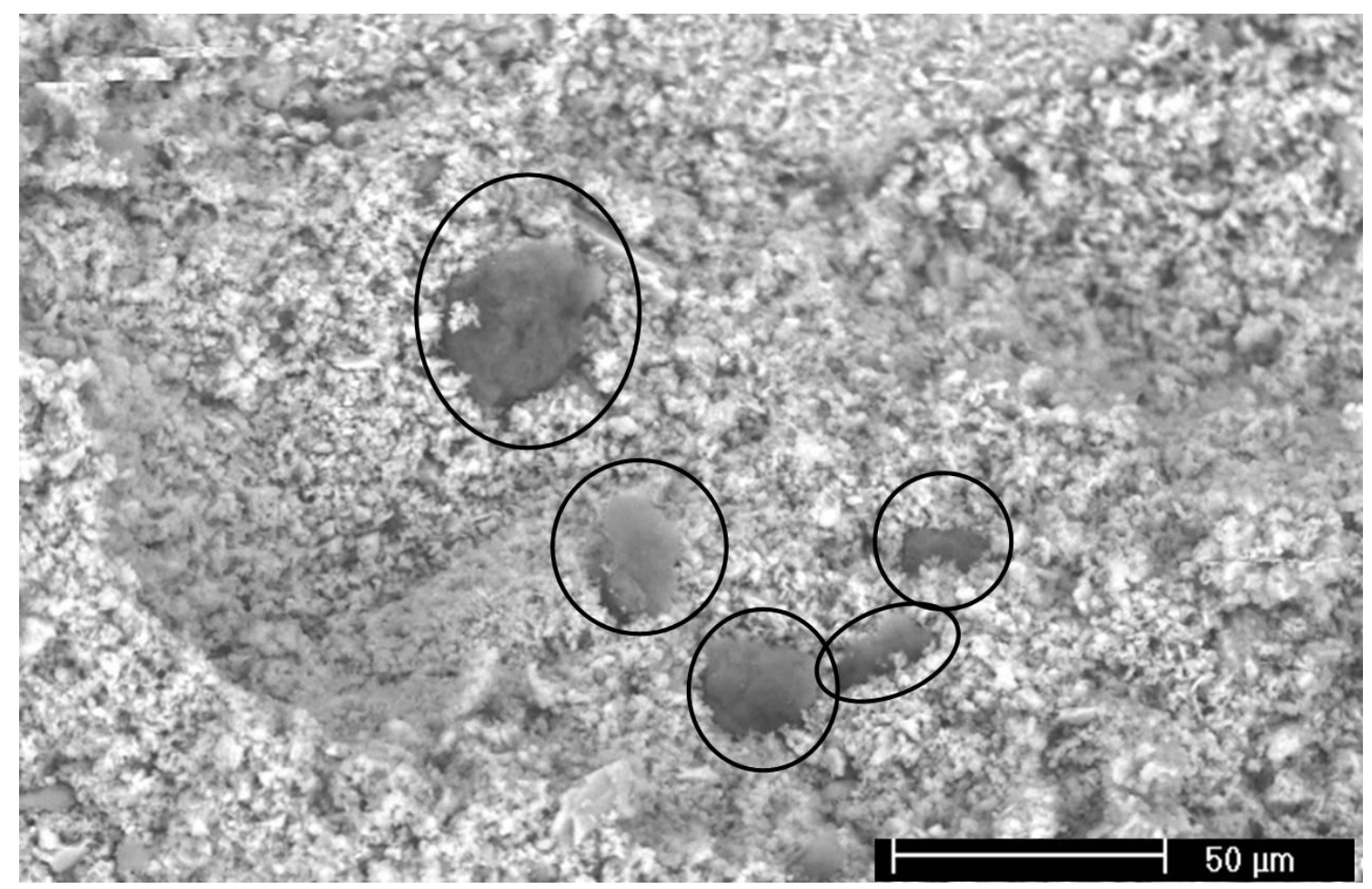

e)

Figure 7. SEM images obtained for different mortars: a) air void with calcium oleate sediment (surrounded with a black line) on its surface in SO-2 mortar; b) calcium oleate sediment in SO-2 mortar; c) air void in CS-2 sample; d) large air bubble in CS-2 mortar; e) group of calcium stearate deposits in CS-2 sample. 

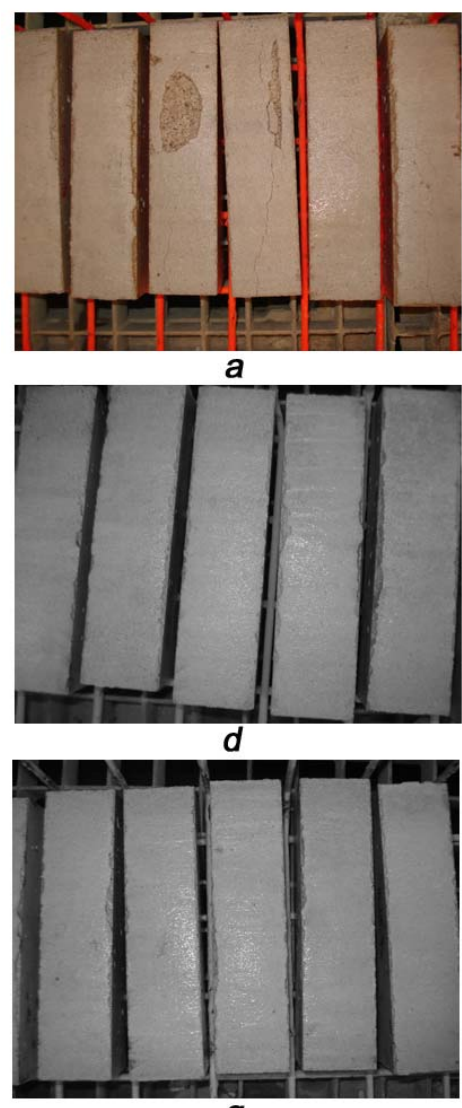

$g$

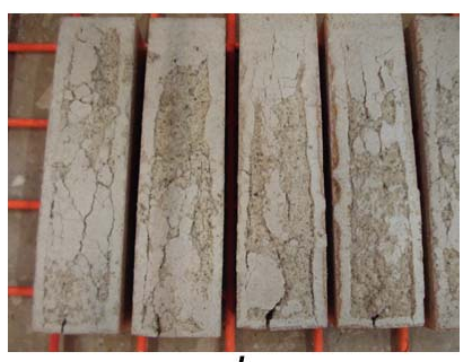

b

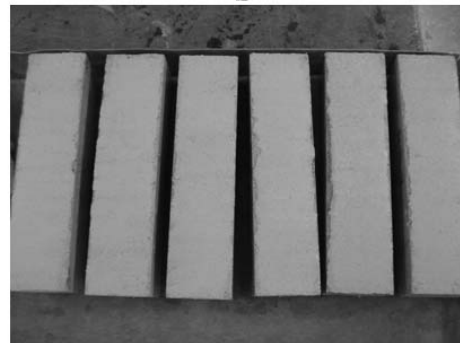

e

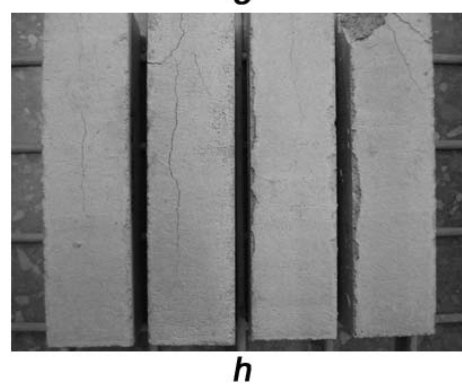

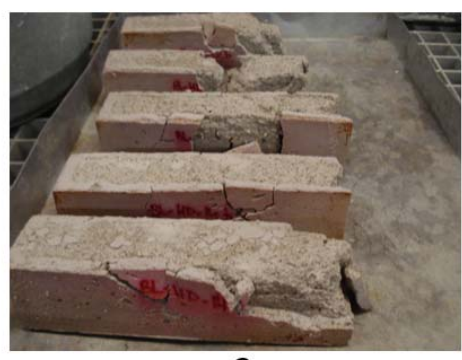

C

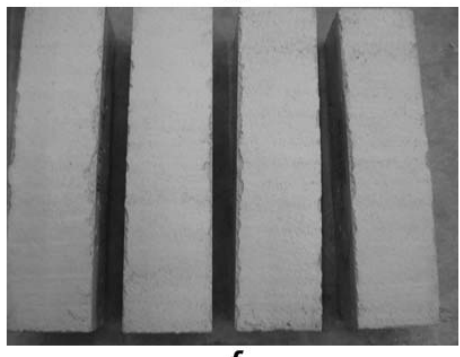

$\boldsymbol{f}$

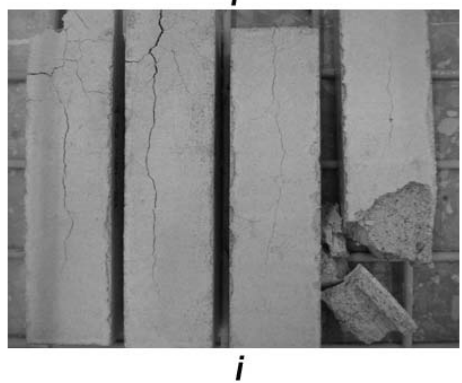

Figure 8: a) Tested specimens after freezing-thawing cycles; a) REF samples after 1 cycle; b) REF samples after 4 cycles, with evidences of alteration; c) REF samples after 6 cycles, totally destroyed; d) SO-2 specimens after 1 cycle; e) SO-2 specimens after 7 cycles; f) SO-2 specimens after 14 cycles showing none sign of deterioration; g) CS-2 samples after 1 cycle; h) CS-2 mortars after 7 cycles, with slight signs of deterioration;

i) CS-2 samples after 8 cycles, with high degree of alteration. 


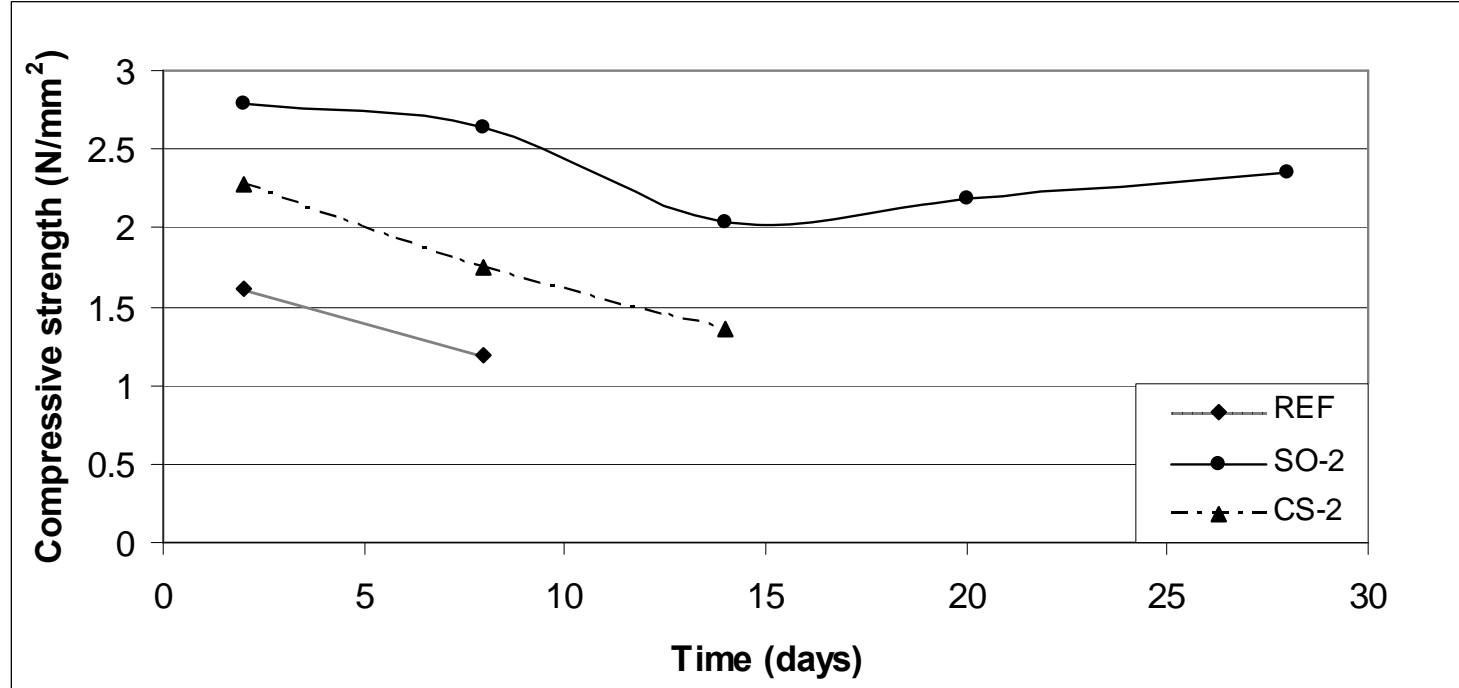

Figure 9. Compressive strength of the mortars after freezing-thawing test. 